\title{
OS GÊNEROS TEXTUAIS E O ENEM: O CURRÍCULO EM AÇÃO
}

\author{
Andréia da Cunha Malheiros SANTANA \\ Programa de Pós-Graduação em Educação- Universidade Estadual de Londrina \\ Andréia Lombardi PEREIRA ${ }^{1}$ \\ Universidade Estadual de Londrina
}

\begin{abstract}
RESUMO: O objetivo deste trabalho é investigar a relação entre o que é prescrito nos documentos oficiais e o que é cobrado no ENEM (Exame Nacional do Ensino Médio), observando se há alguma regularidade ou não nos gêneros selecionados por esta avaliação externa. Segundo Gil (1992), trata-se de uma pesquisa qualitativa, na qual foram analisados os cadernos de Linguagem, Códigos e suas Tecnologias de três edições do citado exame (2012, 2013 e 2014), foram analisadas apenas as questões concernentes à disciplina de Língua Portuguesa. Em seguida, foi feita uma pesquisa documental que buscou identificar os saberes que deveriam ser trabalhados no ensino médio, com este objetivo alguns documentos oficiais foram tomados como referência, como os PCNs (Parâmetros Curriculares Nacionais) e as Diretrizes Curriculares do Paraná. A fundamentação teórica deste estudo foi desenvolvida a partir da leitura de autores como Freitas (2004) e Sousa (2003), sobre as avaliações externas e a sua influência no currículo; Bakhtin (1992), a respeito do trabalho com gêneros discursivos e os documentos oficiais já citados que indicam os conteúdos a serem desenvolvidos durante a educação básica. Como conclusão, apurou-se que, no ENEM, existe uma priorização de gêneros que fazem parte da esfera de circulação Literária/Artística em detrimento de outros, embora os documentos oficiais preguem a valorização de gêneros de diferentes esferas, isto não acontece na prática. Os dados levantados reforçam a importância que, além de trabalhar os conteúdos previstos no exame durante os cursos de formação docente como uma forma de otimizar o desempenho dos estudantes secundaristas, e consequentemente, a democratização do ensino superior, é preciso que tais cursos promovam a leitura crítica dos documentos oficiais que valorizam um tratamento igual aos diferentes gêneros enquanto os processos seletivos ainda privilegiam gêneros e autores consagrados.

PALAVRAS-CHAVE: Gêneros Textuais; ENEM; Formação de Professores
\end{abstract}

ABSTRACT: The objective of this study is to investigate the relationship between what is prescribed in the official documents and what is charged in the ENEM (National Examination of Secondary Education), noting if there is any regularity or not in the genres selected by this external evaluation. According to Gil (1992), it is a qualitative research, in which the language, Codes and their Technologies of three editions of ENEM (2012, 2013 and 2014) were analyzed, only the questions concerning the subject of Portuguese language. Then, a documentary research was done that sought to identify the knowledge that should be worked in high school, with this objective some official documents were taken as reference, such as the National Curriculum Parameters and the Paraná Curricular Guidelines. The theoretical basis was developed from the reading of authors such as Freitas (2004) and Sousa (2003) on external evaluations and their influence on the curriculum; Bakhtin (1992), on the work with discursive genres and the official documents already mentioned that indicate the contents to be developed during the basic education. As a conclusion, it was found that, in the ENEM, there is a prioritization of genres that are part of the Literary/Artistic circulation sphere to the detriment

\footnotetext{
${ }^{1}$ Reescrita de uma pesquisa de iniciação científica finalizada em 2015.
} 
of others, although official documents predict the valuation of genres from different spheres, this does not happen in practice. The data gathered reinforce the importance that, in addition to working on the content of the exam during teacher training courses as a way to optimize the performance of secondary students, and consequently the democratization of higher education, it is necessary that such courses promote reading Criticism of the official documents that value a treatment equal to the different genres while the selective processes still privilege genres and consecrated authors.

KEYWORDS: Textual genres; “ENEM”; Teacher training

\section{Introdução}

O objetivo deste trabalho é investigar a relação entre o que é prescrito nos documentos oficiais e o que é cobrado no ENEM (Exame Nacional do Ensino Médio), observando se há alguma regularidade ou não nos gêneros selecionados por esta avaliação externa.

Os saberes explícitos nos documentos oficiais norteiam o ensino na educação básica assim como os cursos de formação de professores:

O projeto de formação deve ser elaborado e desenvolvido por meio da articulação entre a instituição de educação superior e o sistema de educação básica (...) (BRASIL, 2015, p.05)

I - à integração e interdisciplinaridade curricular, dando significado e relevância aos conhecimentos e vivência da realidade social e cultural, consoantes às exigências da educação básica e da educação superior para o exercício da cidadania e qualificação para o trabalho; (...) (BRASIL, 2015, p.06)

$\mathrm{V}$ - análise do processo pedagógico e de ensino-aprendizagem dos conteúdos específicos e pedagógicos, além das diretrizes e currículos educacionais da educação básica (BRASIL, 2015, p.07)

Tanto na Resolução número 2, de 2015, como as DCNs do curso de Letras, é possível perceber a articulação entre os conhecimentos que integram a educação básica e aqueles que integram a formação do futuro professor:

No caso das licenciaturas deverão ser incluídos os conteúdos definidos para a educação básica, as didáticas próprias de cada conteúdo e as pesquisas que as embasam. (BRASIL, 2001, p.31)

Desta forma, é possível afirmar que os conteúdos cobrados no ENEM influenciam indiretamente a formação de professores, por isso é importante que os estudantes conhecem este exame e os saberes que ele privilegia. É preciso investigar realmente quais os efeitos (impactos) destas avaliações externas (como o ENADE e o ENEM) no âmbito de ensino, a avaliação assumir o papel de nortear o ensino não é um algo novo, Scaramucci fez uso de um trecho de uma reportagem que já apontava esta tendência em 2004: 
"Em São Paulo, por exemplo, as escolas do ciclo médio ensinam aquilo que está no programa da Fuvest, que faz a seleção da USP. Essa situação é bastante indesejável. Afinal, a provada Fuvest não foi concebida para converter-se em diretrizes curriculares, mas apenas para definir quais são os melhores alunos. (Folha de São Paulo, 18/07/2004) (SCARAMUCCI, 2004, p. 204)

O efeito regulador que hoje identificamos no ENEM, outrora era identificado nos vestibulares. Para a autora, algumas vezes o impacto pode ser mais amplo do que se imagina, não se trata apenas da influência do exame no ensino, mas também dos valores que tais avaliações propagam na sociedade.

A autora faz uma síntese de diversas pesquisas que pretendiam identificar o impacto das avaliações no ensino, dentre vários efeitos possíveis, ela destaca o trabalho de Smith (1991, apud Scaramucci, 2004) que destacou que "os programas de avaliação reduziam o tempo que deveria ser devotado à instrução efetiva e conseqüentemente, estreitavam o currículo e os modos de instrução". (p.207). O professor passava mais tempo "treinando" os alunos para terem um bom resultado nas provas e, desta forma, acabam direcionando o aprendizado só para o que era cobrado nas mesmas. Esta reflexão deve ser incorporada à formação de professores, uma vez que as avaliações têm crescido e seus efeitos/ ultrapassaram os seus objetivos explícitos, ignorar o papel das avaliações externas durante os cursos de licenciatura é colaborar para uma formação acrítica dos docentes.

Para compreender melhor o ENEM, antes de o analisarmos, se faz necessário pensarmos no contexto no qual ele está inserido e como este tem favorecido a implantação e o crescimento das avaliações externas.

\section{Contexto Histórico}

O sistema escolar brasileiro deve ser visto como reflexo direto das condições sociais do país, isto é, a escola é nada mais que o resultado do metabolismo social vigente. A década de 1980, em um contexto histórico brasileiro pós-ditadura, foi marcada pelo questionamento referente à estruturação do pensamento progressista em torno das teorias pedagógicas. Na época, havia muitas concepções diferenciadas de educação, cada qual com um objetivo distinto, fragmentando o ambiente educativo em contrastantes conceituações.

Neste período, foram traçados muitos debates sobre os reais fins educacionais e sua fundamentação conceitual, visando um entrelaçamento coerente entre a teoria e a prática educativa. As discussões construídas nesta época resultaram em mudanças profundas concretizadas em 1990; abandonaram-se os modos de organização do processo de trabalho baseados em linhas de produção rígidas que geravam uma produção excessiva de bens e serviços. Tal crise capitalista promoveu uma reformulação organizacional da força de trabalho, incluindo-se a introdução de novas tecnologias.

As mudanças ocorridas marcaram a década com um sentimento de incerteza. Segundo Freitas (2004), as empresas e os profissionais foram profundamente afetados e 6 tiveram de se readaptar ao novo mecanismo social que se voltava para um sistema flexível, ágil (com a 
pressão de se produzir em um tempo cada vez menor) e com foco no cliente. Essa nova organização exigiu cada vez mais do profissional uma qualificação alta para se manter no mercado de trabalho. Assim, emerge, na educação, uma postura neotecnicista, que diz respeito às “(...) competências e habilidades breves e mutantes, no interior de redes abertas, rápidas, virtuais, nas quais se convive mesmo estando isolado no interior de um quarto ante uma tela de computador" (FREITAS, 2004, p. 147).

Freitas afirma ainda que todas as alterações ocorridas após os anos de 1970 resultaram em outras modificações nas relações internacionais e estas, por sua vez, aceleraram o processo de uso da ciência como força produtiva direta. As transformações no plano econômico inspiraram uma visão de sociedade como uma espécie de rede de indivíduos que são ao mesmo tempo conectados e individualizados. De tal concepção criaram-se as redes curriculares de ensino, nas quais se percebe que o aluno é visto como "(...) um cliente a escolher o seu produto final" (FREITAS, 2004, p. 140).

Logo, a educação se tornou uma ramificação capitalista, o que proporcionou um ambiente competitivo entre as escolas e entre os alunos dessas escolas. O aluno é, de modo simultâneo, culpado pelo próprio fracasso e desprovido de reconhecimento individual em caso de sucesso - tendo em vista que as escolas reivindicam para si os triunfos alcançados por seus alunos, mas negam seu papel em situações de baixo rendimento escolar; o mesmo mecanismo é adotado pelo Estado, que toma para si os resultados bons enquanto coloca os ruins como responsabilidade da instituição educacional.

(...) o conceito de avaliação que emergiu privilegiou a avaliação externa em todos os níveis de ensino, sob a lógica da competitividade entre as organizações ou entre os professores, em que a qualidade era produto da própria competição e não uma construção coletiva, a partir de indicadores legitimados socialmente pelos atores (FREITAS, 2004, p. 149).

Todo esse esquema educacional (ainda vigente) foi consequência da influência direta do pensamento progressista, que foi, nos anos de 1990, desconstruído e restituído. Trata-se de um período de questionamento das práticas paradigmáticas antigas - como o pensamento progressista e determinista -, a escola se torna um espaço de transmissão de valores compatíveis com o futuro papel de subordinação dos jovens.

(...) a criação de incertezas pelo capital e sua permanente ação de desconstrução geram no indivíduo um sentimento de impotência com relação ao seu futuro (...), criando um campo favorável à manutenção do status quo, criando a sensação de que (...) não há outra alternativa senão viver o presente e deixar o futuro à sorte. A incerteza cria um campo tão aversivo que o indivíduo sente que é melhor não pensar nele e concentrar-se no agora e, com isso, abrimos mão do futuro para que ele seja planejado por outros, sem obstáculos. A impotência do indivíduo com relação ao futuro é, ao mesmo tempo, a plena potência do capital para pensar seu futuro com total ausência de limites (...). Para o cidadão comum, a luta pela sobrevivência diária retirao do envolvimento e das preocupações com o outro, com as instituições, com os valores, com os princípios, com o coletivo. Dessa forma, enfraquece movimentos sociais, instâncias coletivas de luta, associações de interesses, 
partidos, enfim, fragmenta e mergulha o indivíduo em um profundo narcisismo (FREITAS, 2004, p. 145).

Por fim, na década de 1990, foram criadas algumas práticas que incidiram sobre as ferramentas de exclusão e subordinação. Tratou-se da transformação do chamado Estado-executor para o Estado regulador e o Estado-avaliador, como concluiu Sousa (2003). A escola tomou consciência dos custos econômicos, políticos e sociais da repetência e da evasão. Assim, traçou alguns programas com o intuito de mitigar tais efeitos. Para tal, os alunos que não absorveram o aprendizado não eram mais eliminados da escola, mas permaneceram e puderam participar de programas de correção de fluxo, classes de aceleração ou reforço, entre outros. Dessa forma, ocorreu a internalização dos custos, que segurou o aluno na escola, "empurrou-o" até a conclusão através de programas escolares secundários, evitando a reprovação.

Desta forma, as salas de aula brasileiras foram “(...) extremamente eficientes na obtenção do objetivo para o qual foram criadas, em atendimento à própria estruturação do capitalismo, ou seja, formar para a subordinação, para a obediência" (FREITAS, 2004, p.156). A avaliação surgiu, portanto, como resposta aos mecanismos de controle e responsabilização - conforme afirmou Sousa (2003, p. 178). Neste contexto, a avaliação se tornou uma ferramenta de controle qualitativo.

Os sistemas educativos, então, passaram a sofrer com a filosofia do controle imposta pelas políticas públicas, principalmente a avaliação, como arma para gerar competência e qualidade. Por isso, como colocado por Freitas (2004, p. 148), “(...) a escola e a universidade deixaram de ser percebidas como instituição e passaram a ser entendidas como organização", isto é, a escola se tornou uma prestadora de serviços, não mais um direito público. Tudo aconteceu como se fosse suficiente estar na escola, sem se importar para quê, ou seja, a finalidade da educação foi deixada de lado.

Desde então, os alunos têm sido agrupados e colocados sobre um processo de aprendizagem mecânico e generalizado (FREITAS, 2004). Porém, sabe-se que cada aluno possui seu próprio tempo de absorção cognitiva. Logo, quando submetidos a um único tempo escolar, eles apresentam desempenhos diferentes, dando a ideia de que alguns alunos são menos capazes que outros - concepção essa que deve ser vista como uma deformação da realidade, já que todo aluno possui a mesma capacidade cognitiva e a única diferença se encontra no ritmo.

O processo avaliativo escolar apresenta três componentes. O primeiro deles é o aspecto instrucional, que avalia os conhecimentos do aluno através de provas e trabalhos avaliativos. $\mathrm{O}$ segundo se dá em torno de uma avaliação comportamental, que serve como uma forte ferramenta de controle, no qual o professor pode exigir obediência do aluno para com as regras. $\mathrm{O}$ terceiro é um fator que avalia valores e atitudes, consistindo em "(...) expor o aluno a reprimendas verbais e físicas, comentários críticos e até humilhação perante a classe" (FREITAS, 2004, p. 158).

Os dois últimos componentes são os que atribuem às práticas avaliativas feitas em sala de aula o caráter lógico de subordinação. Eles são dotados de juízos de valor que destroem a autoestima do aluno e, ao invés de ajudá-lo, acaba por prejudicar seu desempenho escolar, na medida em 
que o alunado e o professorado se distanciam e é criado no aluno um sentimento de limitação e subjugação. Um ponto também importante, mas muitas vezes esquecido, diz respeito ao professor, que também é subjugado pelo quadro geral.

Se tradicionalmente o foco (...) era a avaliação da aprendizagem, hoje observamos propostas e práticas que, para além da avaliação do aluno, voltamse para a avaliação do desempenho docente, avaliação do curso, avaliação institucional, avaliação do sistema educacional (SOUSA, 2003, p. 178).

Todas as instâncias dentro do sistema escolar, inclusive a formação de professores, passaram a ser julgadas por um processo avaliativo que, assim como no caso dos alunos, cria um ambiente competitivo, típico do princípio capitalista.

Neste contexto, as avaliações externas se tornaram comuns, pois estas exercem um controle sobre a educação. Entram em cena então exames como o Sistema Nacional de Avaliação da Educação Básica (SAEB), o Exame Nacional do Ensino Médio (ENEM) - objeto deste estudo -, o Exame Nacional de Desempenho dos Estudantes (ENADE) e Prova Brasil - todos efetuados em nível federativo. Tais exames são frutos direto da concretização das políticas educacionais configuradas de modo a responder a concepção vigente de educação como extensão capitalista que deve ser posta sob controle em todos os seus níveis de ensino. As avaliações, dentro do âmbito da educação, encontram a sua justificativa na busca pela qualidade, tal como nos mostra a legislação vigente, contudo controlam (e determinam) a distância dos conteúdos que devem ser trabalhados nas instituições de ensino:

Art. $9^{\circ}$ A União incumbir-se-á de:

VI - assegurar processo nacional de avaliação do rendimento escolar no ensino fundamental, médio e superior, em colaboração com os sistemas de ensino, objetivando a definição de prioridades e a melhoria da qualidade do ensino (BRASIL, 1996).

Nesse estudo, o foco se manterá sobre o ENEM, oficializado em 1998, acreditamos que ele exerce uma função regulatória na educação básica e, ao influenciar os conteúdos desenvolvidos neste nível de ensino, acaba por influenciar a formação de professores, trata-se de uma "rede", na qual um sistema de ensino se atrela ao outro, o que exerce uma força em um ponto também influencia o outro. Também vamos contrapor o que é prescrito nos documentos oficiais para o ensino de Língua Portuguesa e o que é cobrado neste exame. Tudo feito através de um processo metodológico que contempla uma pesquisa documental relacionada com os dados coletados no exame.

\section{O ENEM: o exame do ensino médio}

O ENEM surgiu nesse contexto de proliferação das avaliações externas como um meio de influenciar e controlar o que era trabalhado nas escolas secundárias. Segundo as informações disponibilizadas no site do Instituto Nacional de Estudos e Pesquisas Educacionais Anísio Teixeira (INEP), o ENEM, foi criado com o objetivo de avaliar o desempenho do estudante ao fim da educação básica, buscando, por meio da constatação dos dados levantados através de uma prova, contribuir para a melhoria da qualidade desse nível de ensino. Juntamente com ele, 
houve o desenvolvimento de diversos documentos oficiais que reformularam o currículo incluiu-se nele competências consideradas básicas para a inserção dos jovens na vida adulta -, aumentando, consequentemente, o controle sobre o que é trabalhado no ensino médio.

O que ocorre é que, assim como apontado por Sousa (2003), o ENEM, da forma que é colocado publicitariamente, passa a ideia de que o seu resultado espelha unicamente o desempenho do estudante e seu consequente alcance individual, quando, na verdade, o ENEM reflete as mudanças pelo qual o ensino médio vem passando. Desse modo, como argumentado por Sousa e Oliveira (2003, p. 883), evidencia-se a visão individualizada que domina o processo educacional brasileiro, que atribui “(...) ao aluno, individualmente, a responsabilidade pelas eventuais competências ou incompetências que o exame vier a demonstrar", mostra apenas uma parte da realidade.

\begin{abstract}
Universalizar o Exame Nacional do Ensino Médio - ENEM, fundamentado em matriz de referência do conteúdo curricular do ensino médio e em técnicas estatísticas e psicométricas que permitam comparabilidade de resultados, articulando-o com o Sistema Nacional de Avaliação da Educação Básica SAEB, e promover sua utilização como instrumento de avaliação sistêmica, para subsidiar políticas públicas para a educação básica, de avaliação certificadora, possibilitando aferição de conhecimentos e habilidades adquiridos dentro e fora da escola, e de avaliação classificatória, como critério de acesso à educação superior. (BRASIL, 2014)
\end{abstract}

Como este exame é uma ferramenta de melhoria qualitativa na área da educação, faz-se importante o diálogo com as principais instituições representativas do Brasil, em busca de um aperfeiçoamento constante. Ainda no ano de 2009, foi criado o Comitê de Governança, formado por representantes do Ministério da Educação e Cultura (MEC), juntamente com a participação da Associação Nacional de Dirigentes das Instituições Federais de Educação Superior (Andifes) e do Conselho Nacional de Secretários de Educação (Consed), com objetivo único de discutir e acompanhar o processo de elaboração do ENEM. Em 2012, mais instituições importantes participaram do Comitê, fazendo com que o mesmo fosse instituído novamente em abril. Assim, tal comitê atualmente tem a participação da Secretaria de Educação Básica (SEB/MEC), da Secretaria de Educação Tecnológica (SETEC/MEC), da Secretaria de Educação Superior (SESU/MEC), do Conselho Nacional de Secretários de Educação (CONSED), da União Nacional de Dirigentes Municipais de Educação (UNDIME), do Conselho Nacional das Instituições da Rede Federal de Educação Profissional, Científica e Tecnológica (CONIF), da Associação Nacional de Dirigentes das Instituições Federais de Educação Superior (ANDIFES) e da Associação Brasileira dos Reitores das Universidades Estaduais e Municipais (ABRUEM), o que reforça a ideia de uma "rede" interligando os diferentes sistemas de ensino, uma vez que um tende a influenciar/afetar o outro.

O ENEM é constituído a partir de quatro áreas de conhecimento, agrupadas e reconhecidas nas Matrizes de Referência, disponível no endereço eletrônico do INEP. O exame é dividido em: a) Linguagens, códigos e suas tecnologias, Língua Estrangeira Moderna, Literatura, Artes, Educação Física e Tecnologias da Informação; b) Matemática e suas tecnologias; c) Ciências da Natureza e suas tecnologias, que abrange os conteúdos de Química, Física e Biologia; d) Ciências Humanas e suas tecnologias, abordando os conteúdos de Geografia, História, Filosofia, Sociologia e conhecimentos gerais. 
Nas Matrizes de Referência são colocados cinco Eixos Cognitivos, comuns a todas as áreas de conhecimento abordadas no Exame. Especificamente na área de Linguagens, Códigos e suas Tecnologias, foram traçadas diversas competências, que funcionam como critérios avaliativos. Este documento fornecido pelo INEP tem elencado os objetos de conhecimento associados às Matrizes de Referência de cada área. No campo de Linguagens, apresentam-se como assuntos a serem trabalhados no exame:

- Estudo do texto: as sequências discursivas e os gêneros textuais no sistema de comunicação e informação - modos de organização da composição textual; atividades de produção escrita e de leitura de textos gerados nas diferentes esferas sociais - públicas e privadas.

- Estudo do texto literário: relações entre produção literária e processo social, concepções artísticas, procedimentos de construção e recepção de textos - produção literária e processo social; processos de formação literária e de formação nacional; produção de textos literários, sua recepção e a constituição do patrimônio literário nacional; relações entre a dialética cosmopolitismo/localismo e a produção literária nacional; elementos de continuidade e ruptura entre os diversos momentos da literatura brasileira; associações entre concepções artísticas e procedimentos de construção do texto literário em seus gêneros (épico/narrativo, lírico e dramático) e formas diversas.; articulações entre os recursos expressivos e estruturais do texto literário e o processo social relacionado ao momento de sua produção; representação literária: natureza, função, organização e estrutura do texto literário; relações entre literatura, outras artes e outros saberes. (...)

- $\quad$ Estudo dos gêneros digitais: tecnologia da comunicação e informação: impacto e função social - o texto literário típico da cultura de massa: o suporte textual em gêneros digitais; a caracterização dos interlocutores na comunicação tecnológica; os recursos linguísticos e os gêneros digitais; a função social das novas tecnologias (BRASIL, 2011, p. 14).

O ENEM é composto por quatro provas objetivas, cada qual com 45 questões de múltipla escolha - somando 180 questões -, mais uma produção de texto dissertativa argumentativa. O exame é realizado em dois dias, sendo aplicadas as provas de Ciências Humanas e suas Tecnologias no primeiro dia. Já as de Linguagens, Códigos e suas Tecnologias, bem como a de Matemática e suas Tecnologias, juntamente com a redação, são aplicadas no segundo dia de Exame.

No ENEM, os níveis de dificuldade são distribuídos de modo sistemático, com questões de resolução considerada fácil, média ou difícil. A categoria de discriminação é aferida pela apuração das diferenças entre alunos com habilidades diversas - trata-se de uma comparação e distinção entre os estudantes conforme suas aptidões. E, para consolidar o tripé do método avaliativo, calcula-se a probabilidade de acerto ao acaso, isto é, as respostas dadas por chute. Com o levantamento de cada um dos parâmetros e uma posterior associação entre eles, o participante é classificado conforme seu desempenho e pode, ao receber o boletim, localizar-se na distribuição categórica, tomando conhecimento de seu nível de aptidão em cada umas das quatro áreas avaliadas no Exame.

\section{O que os documentos oficiais determinam}


Posterior à formulação e oficialização dos atuais PCNs, a referência primeira na qual se apoiava a organização curricular do Ensino Médio era o exame de ingresso no Ensino Superior. Então, no ano de 1998, momento da reforma das Diretrizes Curriculares, há uma mudança de perspectiva que passa a almejar maior unificação quanto às competências dos alunos assim como uma maior diversificação quantos aos conhecimentos específicos que alicerçam tais competências.

Validados pelo MEC, os PCNs reformulados no final do século XX, elucidam uma proposta curricular que deve ser o principal guia de trabalho do professor em sala de aula. É ressaltado, no documento, que os docentes devem apropriar-se da proposta não como meramente política, mas também como uma pedagogia norteadora que, quando posta em ação, tenha impacto sobre o ensino. Coloca-se ainda que “(...) o paradigma de currículo proposto não resiste ao enrijecimento e à regulamentação que compõem o estilo dominante de gestão até o presente". O trecho sugere uma dura vistoria e preocupação sobre o êxito da concretização das diretrizes, tendo em vista de que se está a tratar sobre a educação de alunos e a formação de professores.

Dessa dinâmica entre transição e ruptura vai surgir a aprendizagem com os acertos e erros do passado e a incorporação dessa aprendizagem para construir modelos, práticas e alternativas curriculares novas, mais adequadas a uma população que, pela primeira vez, chegará ao Ensino Médio. Esse processo que se inicia formalmente, neste final de milênio, com a homologação e publicação destas Diretrizes Curriculares para o Ensino Médio, não tem data marcada para terminar. Como toda reforma educacional, terá etapas de desequilíbrios, seguidas por ajustes e reequilíbrios (BRASIL, 1998, p. 98).

Os princípios axiológicos, fundamentadores do currículo, devem estar articulados com a legislação, promovendo ao estudante elementos como o exercício da cidadania, a formação de valores e ética, a vinculação da educação à dimensão trabalhista e à prática social, a autonomia intelectual, a capacidade de relacionar teoria e prática. De tal maneira, são designadas três áreas principais que se fazem necessárias na Base Nacional Comum dos currículos das escolas de Ensino Médio, a saber: a) Linguagens, Códigos e suas Tecnologias; b) Ciências da Natureza, Matemática e suas Tecnologias; c) Ciências Humanas e suas Tecnologias. Esse mesmo processo de nuclearização é adotado no exame do ENEM, em compatibilidade com o documento, na Área de Linguagens, Códigos e suas Tecnologias, são traçadas competências concernentes às atividades e conteúdos relacionados às diferentes formas de expressão instância na qual a Língua Portuguesa desempenha papel fundamental. Busca-se deixar em evidência a significação individual de todas as linguagens, essenciais à construção cognitiva, bem como às identidades dos alunos. São contempladas possibilidades artísticas, lúdicas e motoras, não visando, exclusivamente, o conhecimento técnico, mas a competência. Desse modo, o estudante deve saber reconhecer os usos das linguagens e suas aplicações em diferentes situações ou contextos, compreendendo os respectivos interlocutores ou públicos.

Afunilando-se na área de Linguagens, tem-se a imprescindível Língua Portuguesa. Segundo os PCNs, a disciplina, antes dicotomizada em Língua e Literatura, deve trabalhar com o estudo da língua materna em sala de aula, observando e refletindo sobre o uso da língua na vida e na sociedade. $\mathrm{O}$ texto, enquanto unidade básica da linguagem, ganha destaque. $\mathrm{O}$ aluno se torna produtor de textos e deve ser visto como aquele que pode ser entendido pelos textos que produz e que o constituem como ser humano. É exigido, desse modo, que o estudante saiba analisar os recurso expressivos da linguagem verbal, "relacionando textos/contextos, mediante a natureza, 
função, organização, estrutura, de acordo com as condições de produção, recepção (intenção, época, local, interlocutores participantes da criação e propagação das ideias e escolhas, tecnologias disponíveis)" (BRASIL, 1998, p. 24). Nesse momento, portanto, é abordada a questão do gênero textual, tornando-o parte substancial na nova proposta curricular. Tal perspectiva é respeitada e atendida nas Diretrizes Curriculares do Paraná, que adota a ideia de gêneros discursivos trabalhada por Bakhtin.

O aprimoramento da competência linguística do aluno acontecerá com maior propriedade se lhe for dado conhecer, nas práticas de leitura, escrita e oralidade, o caráter dinâmico dos gêneros discursivos. O trânsito pelas diferentes esferas de comunicação possibilitará ao educando uma inserção social mais produtiva no sentido de poder formular seu próprio discurso e interferir na sociedade em que está inserido (PARANÁ, 2008, p.53).

Logo, o trabalho com os gêneros textuais em sala de aula, no Paraná, deve também considerar a língua um instrumento de poder cujo acesso ou crítica é direito para todos os cidadãos. Para tal, faz-se necessário que o aluno tenha um conhecimento coerente sobre os gêneros e suas aplicabilidades, ampliando o uso dos registros socialmente valorizados da língua, como a norma culta. É preciso que o estudante se envolva com os textos que produz, apropriando-se, enquanto autor, do que escreve, ao passo que ele é um sujeito apresentando um enunciado, exercendo sua cidadania de modo legítimo. Em apoio à Bakhtin, que diz "todo enunciado é um elo na cadeia da comunicação discursiva. É a posição do falante nesse ou naquele campo do objeto de sentido" (1992, p. 289). Quanto ao conteúdo estruturante da disciplina de Língua Portuguesa no Ensino Médio, no Estado do Paraná, os gêneros discursivos são colocados em meio a conteúdos ditos básicos.

\section{Definições de gênero textual}

A partir de 1995, houve um aumento significativo nos estudos que exploram as chamadas teorias de gêneros como princípio teórico. Segundo Rojo (2005, p. 184), essa explosão aconteceu, em parte, por conta dos “(...) novos referenciais de ensino de línguas (...)que fazem indicação explícita dos gêneros como objeto de ensino ou destacam a importância de considerar as características dos gêneros, na leitura e na produção dos textos". Desde então, foram várias as contribuições acadêmicas sobre a questão: o que é, afinal, o que chamamos de gênero textual? Tal questionamento propõe uma investigação inegavelmente relevante (e, inclusive, necessária), na medida em que o gênero formata a interação social, sendo tão antigo quanto à própria linguagem.

Vários dos trabalhos desenvolvidos na área tomam como base teórica a proposta bakhtiniana, carregando consigo a ideia central de gênero como "um enunciado de natureza histórica, sociointeracional, ideológica e linguística relativamente estável" (apud Marcuschi, 2005). Bakhtin defende que o enunciado se forma por meio da fusão de três vetores igualmente importantes: o conteúdo temático, o estilo e a construção composicional. E é nessa convergência que nasce os gêneros, com uma seleção específica para cada categoria. É por conta desse caráter integrado que o gênero é fluido e multifacetado, nunca permanecendo o mesmo. "Qualquer enunciado considerado isoladamente, é, claro, individual, mas cada esfera de utilização da língua elabora seus tipos relativamente estáveis de enunciados, sendo isso que denominamos gêneros do discurso (BAKHTIN 1992, p. 279)". Desse modo, o pesquisador os 
agrupa em esferas de circulação, de modo semelhante àquelas citadas na tabela anteriormente referenciada neste projeto.

Para o processo de nucleação de gêneros se faz necessário analisar as condições de produção, de circulação e recepção, na medida em que não se pode desvincular os gêneros da circunstância em que ele se estabelece e atua. Pensando nisso, Bakhtin dividiu os gêneros discursivos em primários - apresentam-se em contextos cotidianos - e secundários - estabelecem-se em situações comunicativas de maior complexidade, como acontece nas áreas jurídicas, artísticas, acadêmicas -; esferas essas que são consideradas por ele como interdependentes. Os gêneros, por muitas vezes, passam por adaptação, transformação, renovação e até mesmo adição de outras características provindas de necessidades atuais. Eles podem nascer ou morrer a qualquer momento, conforme as aplicações exigidas pelas atividades humanas mais recentes. Um exemplo evidente dessa flutuação é o surgimento dos gêneros do discurso eletrônico, como $e$ mail, chat, blogs, sites, videoconferências, ou seja, todo tipo de discurso criado e formatado com os propósitos e usos específicos de um contexto digital. Essa perspectiva de variação dos gêneros, assim como se vê a língua e fala, é uma visão trabalhada por Bakhtin desde 1979.

No Brasil, a reflexão sobre gênero é intensa, com diversas pesquisas no campo da linguística aplicada ao ensino de línguas. A noção conceitual de gênero, hoje, foi ampliada para todo e qualquer tipo de produção textual, ao passo em que o próprio conceito de texto passou a abranger todo diálogo realizado entre um emissor e um receptor. Para Marcuschi (2005) todo o ato linguístico, enquanto manifestação verbal, se realiza como texto, e tais textos são enunciados no espaço das ações sociais situadas e históricas. Logo, o discurso, tanto oral quanto verbal, é caracterizado como uma produção textual, considerando que o ato da fala ou da escrita é como moldar o nosso dizer ou escrever às formas de um determinado gênero, pois "(...) é impossível se comunicar verbalmente a não ser por algum gênero, assim como é impossível se comunicar verbalmente a não ser por algum texto" (MARCUSCHI, 2005, p. 3).

Fruto de trabalho coletivo, os gêneros contribuem para ordenar e estabilizar as atividades comunicativas do dia-a-dia. São entidades sócio discursivas e formas de ação social incontornáveis em qualquer situação comunicativa. No entanto, mesmo apresentando alto poder preditivo e interpretativo das ações humanas em qualquer contexto discursivo, os gêneros não são instrumentos estanques e enrijecedores da ação criativa. Caracterizam-se como eventos textuais altamente maleáveis, dinâmicos e plásticos. Surgem emparelhados a necessidades e atividades socioculturais, bem como na relação com inovações tecnológicas (...) (MARCUSCHI, 2005, p.1).

Logo, infere-se que o gênero não tem caráter estável devido a seu parentesco linguístico, por estar sempre acompanhando a constante evolução da língua - fator que torna importante frisar o aspecto sócio funcional de gênero. Bazerman (1994 apud Marcuschi, 2004) afirma que "gêneros são o que as pessoas reconhecem como gêneros a cada momento do tempo, seja pela denominação, institucionalização ou regularização. Os gêneros são rotinas sociais de nosso diaa-dia".

O termo gênero é usado por Fairclough para designar "um conjunto de convenções relativamente estável que é associado com, e parcialmente realiza, um tipo de atividade socialmente aprovado, como a conversa informal, a compra de produtos em uma loja, uma entrevista de emprego, um documentário de televisão, um poema ou um artigo científico" (...). Além disso, "um gênero implica não somente um tipo particular de texto, mas 
também processos particulares de produção, distribuição e consumo de textos". Cada gênero, portanto, ocorre em determinado contexto e envolve diferentes agentes que o produzem e consomem (lêem e interpretam) (ROJO, 2001, p. 81-82).

Na mesma perspectiva acadêmica, Marcuschi (2002) configura o texto como uma espécie de entidade concreta realizada materialmente e corporizada em algum gênero textual. Ideia esta que reafirma os gêneros como uma função organizacional referente à estrutura dos textos e suas respectivas aplicabilidades - essas que, por sua vez, também variam constantemente, fazendo com que os gêneros se desenvolvam de forma a acompanhar tais mudanças.

\begin{abstract}
Hoje, em plena fase da denominada cultura eletrônica (...) presenciamos uma explosão de novos gêneros e novas formas de comunicação, tanto na oralidade como na escrita. Isto é revelador do fato de que os gêneros textuais surgem, situam-se e integram-se funcionalmente nas culturas em que se desenvolvem. (...) Quase inúmeros em diversidade de formas, obtêm denominações nem sempre unívocas e, assim como surgem, podem desaparecer (MARCUSCHI, 2002, p. 1).
\end{abstract}

Dessa forma, classificar rigidamente o que entendemos como gênero, bem como discursa Bazerman (apud Marcuschi, 2004) é se entregar a um formalismo reducionista. Marcuschi, por sua vez, adiciona ainda que não devemos ver os gêneros como estruturas inflexíveis e imutáveis, mas sim como entidades dinâmicas, sendo eles formas culturais de ação social corporificadas de um modo particular na linguagem. Por conta da relação direta com a organização social, suas funções, atividades e influências, os gêneros, assim como a própria língua, variam, adaptam-se, renovam-se e multiplicam-se. Portanto, as nossas definições de formas genéricas sempre terão curta duração, devendo-se respeitar essa característica dos gêneros sem limitá-los às rasas questões linguísticas ou discursivas.

\title{
O ENEM em análise
}

A presente pesquisa pode ser classificada como uma pesquisa documental, com uso de métodos mistos. Para Gil (2002), a categorização de uma pesquisa não deve ser inflexível, na medida em que é comum que algumas pesquisas tenham características que permitam que sejam classificadas em mais de uma categoria. A presente pesquisa faz um levantamento quantitativo dos gêneros citados e cobrados no ENEM. A informação quantitativa permite uma melhor explanação da importância atribuída aos gêneros textuais nesta avaliação externa. Essa pesquisa fundamenta-se na análise e relação de informações advindas da leitura de documentos oficiais, como as Diretrizes Curriculares, os Parâmetros Curriculares (PCNs) e outros, incluindo também a produção bibliográfica sobre a temática. Além destas fontes, a pesquisa conta com a análise do referido exame nas suas três últimas edições, a saber 2014, 2013 e 2012 - com a informação quantitativa pôde-se afirmar quais gêneros são mais valorizados, aparecendo com maior frequência ou exploração, pela citada avaliação. Tal método também permitiu a constatação de regularidade ou não no tratamento dado aos gêneros ao longo dos três últimos anos. 


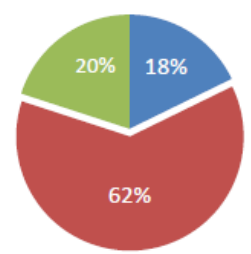

Aspecto Linguístico

— Leitura (literária ou não)|

- Outras disciplinas

ENEM 2012

Figura 1 - Gráfico de análise geral (ENEM 2012)

Dentre as 45 questões analisadas no ENEM 2012, compreendeu-se que 9 questões (20\%) da categoria se referiam a outras disciplinas que não a Língua Portuguesa, como Língua Estrangeira, Artes e Educação Física - questões que não foram analisadas. 08 questões (18\%) trabalharam com um aspecto linguístico, que pediam uma resposta desvinculada de leitura profunda ou interpretação do texto, momento no qual o aluno, para resolver a questão poderia ou fazer um escaneamento superficial do texto para encontrar as informações necessárias e somente apontá-las ou recorrer a conhecimentos cabíveis à Gramática Tradicional e Semântica para categorizar um trecho do texto desvinculado de seu contexto. Outras 28 questões, com peso de $62 \%$, (relevantes para essa pesquisa), exigiram leitura atenta bem com a interpretação e posterior associação com outros conhecimentos para uma resposta de maior complexidade. $\mathrm{O}$ que aponta uma valorização das questões que trabalham com a leitura em detrimento da análise linguística.

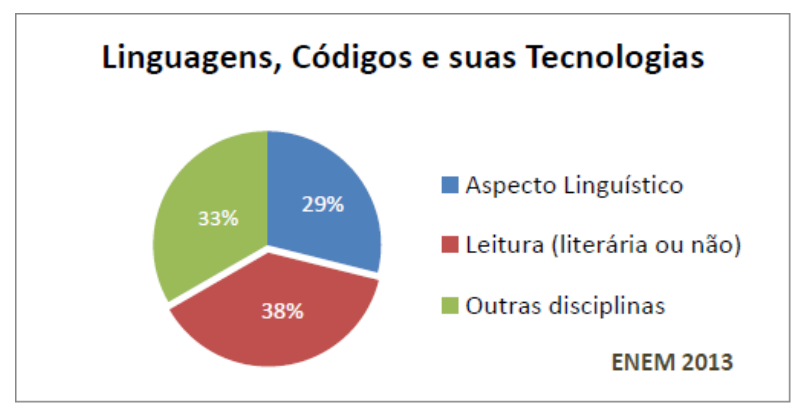

Figura 2. Gráfico de análise geral (ENEM 2013)

No exame de 2013, das 45 questões totais, 15 delas (33\%) não competem à matéria de Língua Portuguesa e outras 13 (29\%) pediam uma resposta no nível do texto, isto é, uma leitura menos analítica e mais técnica, explorando mais uma análise linguística. De resto, 17 questões (38\%) exigiram uma análise de maior grau do aluno para que o mesmo pudesse elaborar a resolução eficientemente, trabalhando com a prática da leitura em diferentes níveis. Ao relacionarmos os dados de 2012 com os de 2013, é possível constatar um maior equilíbrio entre as questões, mesmo que ainda percebamos a prevalência de questões que demandem leitura.

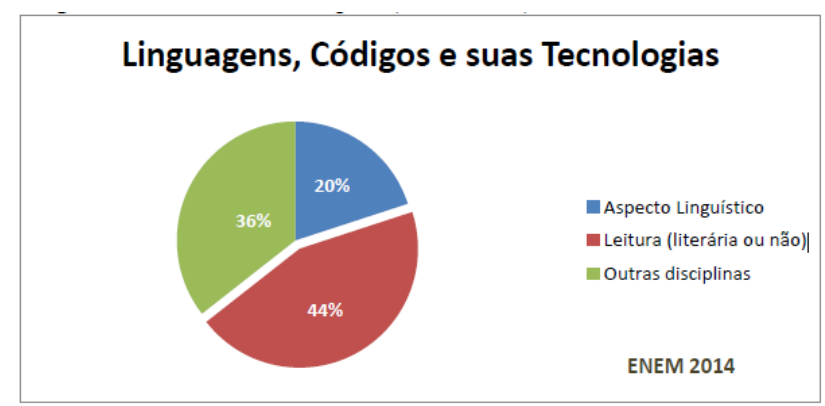


Figura 4 - Gráfico de análise geral (ENEM 2014).

No ENEM 2014, foram analisadas 45 questões, das quais 16 questões (36\%) faziam referência a outras disciplinas e outras $9(20 \%)$ trabalhavam com um aspecto linguístico ou uma leitura mais superficial. Por fim, destacamos 20 questões (44\%) concernentes a Língua Portuguesa que requeriam maior interpretação e atividade cognitiva.

Ao analisarmos as três edições do ENEM, podemos perceber que o número total de questões se manteve (45). Contanto, houve um aumento claro de questões destinadas às outras disciplinas que integram a área - de 09 questões (2012) para 15 (2013) e 16 (2014) - o que resulta em um maior equilíbrio entre as disciplinas, embora a disciplina de português ainda responda a, aproximadamente, $67 \%$ da nota do exame. Na disciplina referente à Língua Portuguesa também é possível apontar uma tendência a valorizar os conhecimentos advindos de leitura e análise literária em oposição ao conhecimento linguístico, previamente adquirido pelo aluno: na edição de 2012, 28 questões foram feitas com estes objetivos, em 2013 foram 17 e em 2014, 20. Ou seja, a ênfase da prova de português é, dessa forma, a leitura.

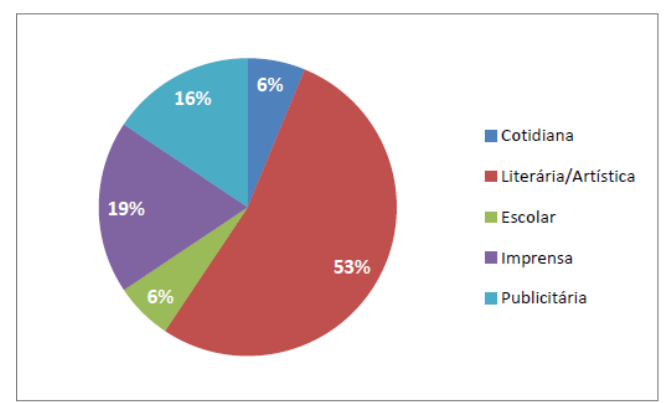

Figura 4 - Gráfico dos gêneros trabalhados conforme suas esferas de circulação (ENEM 2012).

Segundo as esferas de circulação, os gêneros trabalhados pelo exame nessas questões foram:

- Esfera Cotidiana: Letra de música;

- Esfera Literária/Artística: poesia, conto, crônica, texto poético, letra de música, pintura, romance;

- Esfera Escolar: texto teórico;

- Esfera de Imprensa: charge, tira, tabela, carta de leitor, entrevista;

- Esfera Publicitária: anúncio, coluna, cartaz.

Notou-se que os gêneros que apareceram com maior frequência foram a poesia (em 05 questões) e o texto poético (em 04 questões).

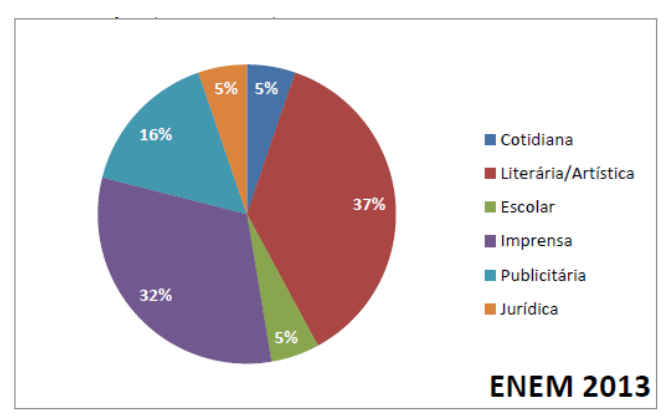


Figura 5- Gráfico dos gêneros trabalhados conforme suas esferas de circulação (ENEM 2013).

No ano 2013, foram abordados os seguintes gêneros, segundo as esferas:

- Esfera Cotidiana: carta;

- Esfera Literária/Artística: carta, pintura, poesia, romance;

- Esfera Escolar: carta;

- Esfera de Imprensa: teatro, poema, artigo de opinião, cartum, charge, tira;

- Esfera Publicitária: texto informativo, cartaz;

- Esfera Jurídica: lei.

Aparecem mais frequentemente o gênero da poesia (em 03 questões), do romance (02 questões) e do cartaz publicitário (02 questões).

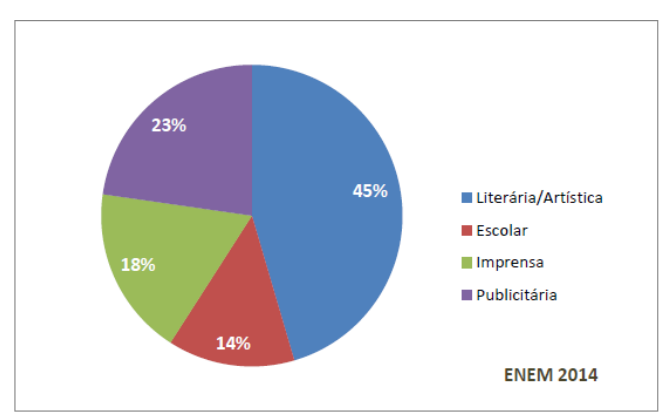

Figura 6 - Gráfico dos gêneros trabalhados conforme suas esferas de circulação (ENEM 2014).

As questões referidas acima no gráfico trazem consigo os seguintes gêneros, segundo as esferas de circulação de cada:

- Literária/Artística: romance, poesia, crônica;

- Escolar: texto teórico;

- Imprensa: notícia, artigo de opinião, editorial, charge;

- Publicitária: cartaz, anúncio.

Dentre os gêneros acima, o romance apareceu com maior frequência (05 vezes), seguido pela poesia e cartaz (ambos foram apresentados em 04 questões).

Ao fim da análise das três edições do ENEM, notou-se que os gêneros pertencentes à esfera Literária/Artística aparecem com maior frequência nos exames, fundamentando $53 \%$ das questões de Língua Portuguesa em 2012, outros 37\% na prova de 2013, bem como $45 \%$ em 2014. Em todos os anos, com a análise apreendida foi possível perceber que dois gêneros dessa esfera foram usados nos três anos trabalhados: o romance e a poesia; evidenciando, assim, uma tendência do exame em abordá-los. A crônica e a pintura também se mostraram frequentes, porém em uma quantidade inferior, menos recorrente. Outras esferas de circulação bastante adotadas no exame: a Imprensa (19\% em 2012, 32\% em 2013 e 18\% em 2014) e a esfera Publicitária (16\% em 2012 e 2013, mais 23\% em 2014). Referentes a essas esferas, foram abordados nos três anos os gêneros charge e cartaz; com menor frequência, trabalhou-se com o gênero tira, anúncio e artigo de opinião, onde cada um apareceu em, pelo menos, dois dos anos examinados. 


\section{Conclusão}

Ao concluir os levantamentos estatísticos explanados anteriormente, observou-se que em 2012 a disposição das disciplinas no caderno de Linguagens, Códigos e suas Tecnologias, foi feita de modo não equilibrado, com a parcela de $80 \%$ sobre o total - número referente somente ao estudo de Língua Portuguesa. Nos anos seguintes, houve uma maior distribuição temática, aumentando as questões concernentes às matérias de Língua Estrangeira, Artes e Educação Física, representadas por 33\% das questões em 2013 e 36\% em 2014. Entretanto, nos três exames, observou-se que, dentro do trabalho sobre Língua Portuguesa, houve uma priorização de questões que exigiam leitura, literária ou não, abordagem essa que foi usada, em média, duas vezes mais do que a referente ao estudo linguístico.

Desse modo, com a constante abordagem interpretativa usada nas questões, que foram trabalhadas, em sua grande maioria, com a poesia e o romance, da esfera Literária/Artística, foi possível concluir que existe sim uma regularidade (e, portanto, uma priorização) no exame ENEM quanto aos gêneros selecionados. Fator este que denota um trabalho focalizado em certos gêneros e suas respectivas esferas, diminuindo e tornando secundários, como consequência, outros gêneros.

Foi possível concluir que, embora os documentos oficiais preguem a diversificação dos gêneros no ensino médio, o ENEM vem realizando uma seleção tendenciosa de gêneros a serem cobrados no exame. É necessário um maior alinhamento com os documentos oficiais que prescrevem o conteúdo a ser abordado no ensino médio brasileiro. Tendo em vista o objetivo $a$ piori do ENEM de avaliar a educação básica, observa-se uma contradição inferida a partir dos levantamentos dessa pesquisa; isto é, trata-se de uma convergência clara entre o currículo e a avaliação externa, o ENEM; os dois em direto diálogo.

\section{Referências}

BAKHTIN, Michail (Volochinov). Estética da Criação Verbal. São Paulo: Martins Fontes, 1992.

BRASIL. Ministério da Educação. Secretaria da Educação Básica. Lei De Diretrizes e Bases da Educação 9394. Brasília: MEC, 1996. Disponível em: <http://www.planalto.gov.br/ccivil_03/leis/19394.htm>. Acesso em: 23 set. 2014.

BRASIL. Ministério da Educação. Secretaria da Educação Básica. Lei de Aprovação do PNE - Plano Nacional de Educação. Brasília: MEC, 2014. Disponível em: http://www.planalto.gov.br/ccivil_03/_Ato2011-2014/2014/Lei/L13005.htm. Acesso em: 27 fev. 2015.

BRASIL. Ministério da Educação. Secretaria da Educação Básica. Parâmetros Curriculares Nacionais (Ensino Médio). Brasília: MEC, 1998. Disponível em: <http://portal.mec.gov.br/seb/arquivos/pdf/blegais.pdf>. Acesso em: 23 jun. 2015.

BRASIL. Ministério da Educação. Secretaria da Educação Básica. Parâmetros Curriculares Nacionais (Ensino Médio): parte II - Linguagens, Códigos e suas Tecnologias. Brasília: MEC, 1998. Disponível em: < http://cptstatic.s3.amazonaws.com/pdf/cpt/pcn/linguagem-codigos-esuas-tecnologias.pdf>. Acesso em: 23 jun. 2015. 
BRASIL, Instituto Nacional de Estudos e Pesquisas Educacionais Anísio Teixeira. ENEM: Sobre o ENEM. Brasília, 2011. Disponível em: <http://portal.inep.gov.br/web/enem/sobre-oenem>. Acesso em: 23 set. 2014.

BRASIL, Instituto Nacional de Estudos e Pesquisas Educacionais Anísio Teixeira. ENEM: Comitê de Governança. Brasília, 2011. Disponível em: <http://portal.inep.gov.br/web/enem/comite-de-governanca>. Acesso em: 24 set. 2014

BRASIL, Instituto Nacional de Estudos e Pesquisas Educacionais Anísio Teixeira. ENEM: Conteúdo das provas - Matrizes de Referência. Brasília, 2011. Disponível em: <http://portal.inep.gov.br/web/enem/conteudo-das-provas>. Acesso em: 24 set. 2014

BRASIL, Instituto Nacional de Estudos e Pesquisas Educacionais Anísio Teixeira. ENEM: Provas e gabaritos. Brasília, 2011. Disponível em: $<$ http://portal.inep.gov.br/web/enem/edicoes-anteriores/provas-e-gabaritos>. Acesso em: 23 set. 2014.

BRASIL, Resolução no. 02. Define as Diretrizes Curriculares Nacionais para a formação inicial em nível superior. Disponível em:

http://portal.mec.gov.br/index.php?option=com_docman\&view=download\&alias=17719-rescne-cp-002-03072015\&category_slug=julho-2015-pdf\&Itemid=30192 Acesso em 15 nov. 2016.

FREITAS, Luiz Carlos de. A avaliação e as reformas dos anos de 1990: novas formas de exclusão, velhas formas de subordinação. Educação Social, Campinas, vol. 25, n. 86, p. 133 170, abril 2004.

GIL, Antônio Carlos. Como elaborar projetos de pesquisa. 4. ed. São Paulo: Atlas, 2008. 175 $\mathrm{p}$

MARCUSCHI, Luiz A. Gêneros Textuais: Configuração, Dinamicidade e Circulação. In: KARWOSKI, B. G.;BRITO, K.S. Gêneros Textuais: Reflexões e Ensino. Palmas e União da Vitória, PR: Kaygangue, 2005.

PARANÁ. Departamento de Educação Básica. Secretaria de Estado da Educação do Paraná. Diretrizes Curriculares da Educação Básica: Língua Portuguesa. Paraná: DEB, 2008. Disponível em: <http://www.educadores.diaadia.pr.gov.br/arquivos/File/diretrizes/dce_port.pdf >. Acesso em: 23 jun. 2015.

ROJO, Roxane. Gêneros do discurso e gêneros textuais: questões teóricas e aplicadas. In: MEURER, J. L., BONINI, Adair, MOTTA-ROTH, Désirée (orgs.). 2. ed. Gêneros: teorias, métodos, debates. São Paulo: Parábola Editorial, 2005. p. 184-207.

SCARAMUCCI, M. V.R. Efeito Retroativo da Avaliação no Ensino/Aprendizagem de Línguas: O Estado da Arte. In: Trab. Ling. Aplic. Campinas, 43 (2), 2004: 203-226. Disponível em http://www.scielo.br/pdf/tla/v43n2/a02v43n2.pdf Acesso em 19 nov de 2016.

SOUSA, Sandra Zákia Lian. Possíveis impactos das políticas de avaliação no currículo escolar. Cadernos de Pesquisa, n. 119, p. 175-190, jul. 2003. 
SOUSA, Sandra Zákia Lian; OLIVEIRA, Romualdo Portela de. Políticas de avaliação da educação e quase mercado no Brasil. Educação Social, Campinas, vol. 24, n. 84, p. 873-895, set. 2003. 